\title{
Üniversite Hastanesine Geriatrik Hasta Başvuruları ve Endodontik Tedavi İnsidanslarının İncelenmesi
}

\author{
Evaluation of Admissions and Incidence of Endodontic Treatment of Geriatric Patients in a \\ University Hospital
}

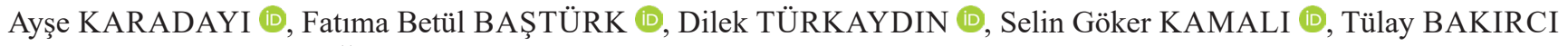
(D), Hesna Sazak ÖVEÇOĞLU (D)

Öz

Amaç: Çalışmamızın amacı, bir üniversite hastanesine başvuran geriatrik hastaların popülasyonunu ve kök kanal tedavilerinin insidansını değerlendirmektir.

Gereç ve yöntem: Ocak, Şubat ve Mart 2019'da Marmara Üniversitesi Diş Hekimliği Fakültesi'ne başvuran hasta sayısı elde edilmiştir. Bu hastalar arasından 65 yaş ve üzeri olan hastalar belirlenmiştir. Hastalar cinsiyete ve yaşa göre temelde iki gruba ayrılmıştır. Daha sonra bu hastalar içerisinden 65 yaş üstü 50 hasta rastgele seçilmiştir. Yaş kategorisinde genç yaşlilar (6574), yaşlılar (75-84), çok yaşlılar (85 ve üstü) bulunmaktadır. Her hastanın panoramik röntgenleri tek bir araştırmacı tarafından incelenmiş ve kök kanal tedavileri tespit edilmiştir.

Bulgular: Toplam 2762 hasta yeni giriş yapmıştır. Bu hastalar içerisinde 185 birey geriatrik hastadır. Gruplar; 65-69, 70-74, 75-79 yaş arası hastalardan oluşmaktadır. 65-69 yaş arası 100 bireyin 36'sını kadın, 64'ünü erkek hastalar oluşturmaktadır. 7074 yaş arası 61 bireyin 26's kadın 35'i erkektir. 75-79 yaş arası 19 hastanın ise 9'u kadın 10'u erkektir. Fakülteye son 3 ayda 80 yaş ve üzeri sadece 5 hasta girişi olduğu görülmüştür. Rastgele seçilen 50 geriatrik hasta içerisinde ise 65 yaşından büyük 50 hastadan 22'si erkek, 28'i kadındı. 65-74 yaş grubuna ait birey sayısı 39, 7584 yaş grubuna ait birey sayıs 9,85 yaş ve üzeri birey sayısı ise 2 'dir. Gruplarda kanal tedavisi görmüş hastaların sayısı sırasıyla 18,5 ve 1 'dir.

\section{Ayşe KARADAYI * \\ aysekaradayi07@icloud.com \\ Fatıma Betül BAŞTÜRK* ${ }^{*}$ ( $)$ \\ fatimabasturk@gmail.com \\ Dilek TÜRKAYDIN* \\ erbaydilek@yahoo.com \\ Selin Göker KAMALI* \\ dtselingoker@gmail.com \\ Tülay BAKIRCI* \\ tulaybakirci@outlook.com \\ Hesna Sazak ÖVEÇOĞLU* \\ hsazak@marmara.edu.tr}

"Marmara Üniversitesi Diş Hekimliği Fakültesi, Endodonti Anabilim Dalı Submitted / Gönderilme: 25.12.2019 Accepted/Kabul: 27.12.2019
Sonuç: Hastaların yaşı arttıkça kök kanal tedavilerinin sayıs1 azalmaktadır. $\mathrm{Bu}$ durumun sebebinin, toplumumuzda artan yaşla birlikte ağızdaki diş sayısının azalması olabileceğini düşünmekteyiz.

Anahtar Kelimeler: endodonti, geriatri, kök kanal tedavisi

\section{Abstract}

Aim: The aim of our study was to assess the number of root canal treatments amongst geriatric patients admitted to a university hospital.

Materials and methods: The number of patients admitted to Marmara University Faculty of Dentistry in January, February and March 2019 was obtained. Among these patients, patients aged 65 years and over were identified. Patients were basically divided into two groups according to gender and age. Age categories were 6569, 70-74 and 75-79.

Then fifty patients over the age of 65 were selected randomized. The patients were subdivided into two categories; according to gender and age. The age category included young olds (65-74), old olds (75-84), oldest olds (85 and over). The panoramic x-rays of each patient were examined by a single operator and root canal treatments were detected.

Results: A total of 2762 patients have just admitted. Among these patients, 185 were geriatric. Groups; It consists of patients between the ages of $65-69,70-74,75-79$. Of the 100 patients aged 65-69 years, 36 were female and 64 were male. Of the 61 patients aged 70-74, 26 were female and 35 were male. Of the 19 patients aged 75-79, 9 were female and 10 were male. In the last 3 months, only 5 patients aged 80 and over were admitted to the faculty.

Amongst 50 selected patients who were over the age of 65,22 were male and 28 were female. The number of young olds were 39 , old olds were 9 and the oldest olds were 2 . The greatest number of root canal treatments were observed in the young olds category $(n=19)$ followed by old olds $(n=5)$ and only 1 root canal

treatment was observed in the oldest old category.

Conclusion: The number of root canal treatments decrease as the age of the patients increase, suggesting that incidence of edentulism and becoming toohtlessness is still high amongst geriatric patients.

Keywords: endodontics, geriatrics, root-canal treatment 


\section{Giriş}

Yaşl1lık ile ilgili kullanılan terimler Geriatri ve Gerontoloji'dir. Geriatri, yaş sağlığı konusunu da içeren, yaşl1lık bilimi olarak incelenir. Gerontoloji ise yaşlanma olayını konu eden eden ve yaşlanma fizyolojisiyle ilgilenen bir bilim dalıdır (1).

Yaşlılık; çocukluk, gençlik, orta yaş dönemi gibi insan hayatının doğal bir sürecidir. Bireyin hayatının tüm aşamalarında metabolizması, vücut fonksiyonları, psikolojisi ve sosyal ilişkileri değişime uğramaktadır. Bu sebeple yaşlılık bir hastalık değil, kendine has özellikleri olan fizyolojik bir süreçtir. Yaşlılıkta, kişilerin fiziksel, ruhsal ve fonksiyonel durumlarının geri dönüşümsüz olarak aşamalı bir şekilde kaybolduğu görülür (2).

Her ne kadar yaşlanma açısından kesin bir sınır teşkil etmese de, bir çok batı ülkesinde 65 yaş, geriatrik yaş sınırı olarak kabul edilmektedir. Dünya Sağlık Örgütü psikogeriatrik yaşlılık dönemi için 65 yaş ve üstünü yaşl1, 85 yaş ve üzerini çok yaşlı olarak kabul etmektedir. (3-4-5).

Dünyamız gün geçtikçe yaşlanmaktadır. Doğum oranındaki azalma ile birlikte yaşam standartları iyileşmekte, insan ömrünün uzamakta ve yaşlı nüfus giderek artmaktadır. DSÖ' nün 1970-2025 yıllarındaki nüfus projeksiyon öngörülerine göre yaşlı insan oranı \%22,3 ile 624 milyon olarak beklendiği; 2025 yılında 1,2 milyon insanın 60 yaş ve üzeri yaşta olacağ 1 ve 2050 yılında ise yaklaşık 2 milyon olması öngörülen yaşlı nüfusunun \%80'inin gelişmekte olan ülkelerde olacağı beklenmektedir. 2002 yılında yapılan çalışmalara göre gelişmekte olan ülkelerdeki 60 yaş üzeri insan sayısı 400 milyon iken, 2025 yılında 840 milyona ulaşacağ tahmin edilmekte ve yaşlıların \%70'inin gelişmekte olan ülkelerde özellikle de Asya kıtasında olacağı beklenmektedir (6).

1955 yılında yaşlı nüfusun toplam nüfusa oranı $\% 3,4$ iken 2010 y1lındaki nüfus sayımında bu oran \%7,1, 2012 de ise $\% 7,5$ 'e yükselmiştir. TÜİK nüfus izlemine göre bu oranın 2023 yılında yaklaşı \% $\% 10.2$ ve 2050 de ise $\% 20.8$ olacağ 1 beklenmektedir (7-8). Yapılan çalışmalar, 21. yüzyılın tüm dünyadaki getirilerine paralel olarak Türkiye'de de yaşlı yüzyılı olacağını göstermektedir (8-9).

Toplam nüfus içinde 65 yaş üstü kişilerin oranı, 5 yaş altı çocukların oranından fazladır (10). Avrupa kıtası, yaşlanmada üst sıralardadır ve 2040 ' da her dört Avrupalıdan birinin 65 yaş üzerinde 6 olacağ 1 beklenilmektedir (16). OECD ülkeleri arasında en hızlı yaşlanan ülke ise ülkemizdir (11).
Özellikle gelişmiș ülkelerde, Dünya nüfusu yaşlı nüfusa doğru kaymaktadır. (12).

Yirminci yüzyılın başında ortalama insan ömrü 50 yaşın altındaydı. Türkiye için Türkiye İstatistik Kurumu (TUIK) 2015-2017 nüfus verilerine göre insan ömrü ortalama 78 senedir Türkiye istatistik kurumu (TÜİK) verilerine göre 65 yaş üstü nüfusun, tüm nüfusa oran 2000 yılında $\% 6,7 \mathrm{iken}$, 2010 'da \% $7.2,2014$ 'de \%8 ve 2015 'de \%8.2 olarak tespit edilmiştir. 2017'de Dünya nüfusunun \%8.9'unu geriatrik hastalar oluştururken, 2017 TUIK verilerine göre ülkemizde geriatrik nüfusun toplam nüfus içindeki oran $1 \% 8,5^{\prime}$ tir.

Türkiye'de yaşlı nüfus oranı son 5 y1lda $\% 17$ artmıștır. 2023 yılında ise bu oranın \%10.2 olacağı tahmin edilmektedir. Buradan çıkan sonuç ise nüfusumuz hızla yaşlanmakta olduğudur (13).

Super-ager olarak tanımlanan ve bilişsel olarak herhangi bir kayıp göstermeyen günlük fiziksel aktivitelerini de belli ölçüde gerçekleştirebilen bireylerin de varlığı unutulmamalıdır. Dünya üzerinde hayat standartlarının günden güne yükseldiği düşünülürse bu hastaların oranının artacağ ${ }_{1}$ göz ardı edilmemelidir. Bu sebeple, kliniğe gelen geriatrik hastaların gözlem ve muayenelerinin dikkatle yapılması ve bireye uygun tedavi planının kapsamlı bir geriatrik değerlendirme ile oluşturulması gerekmektedir (14-15).

Yaşla beraber ağıziçerisinde tükürük akışının yavaşladığı, periodontal kemik kaybı olduğu ve genel olarak bilişsel zekanın azalmaya başladığı bilinmektedir (16-17-18-1920). Yaşlıda ağız hijyeni gençlerdeki kadar iyi değildir(21). Bu duruma yol açan bir çok faktör bulunmaktadır. Öncelikli olarak yaşlı bireyler kognitif fonksiyonlarının azalması, artrit, geçirilmiş kazalar ya da serebrovasküler atak gibi nedenlerle manüplasyon yeteneklerini önemli ölçüde yitirmişlerdir(21). Bu yüzden ağız hijyeni sağlamaları kolay değildir. Ağız mukozasında tükürük akış hızındaki azalmaya bağlı kuruluk meydana gelir.(22). İlerleyen yaşla birlikte periodontal dokular plağa daha çok maruz kalır, diş eti çekilmesi artar. Estetik ve dental sorunlar oluşur (23-2425).

$\mathrm{Bu}$ çalışmanın amacı üniversite hastanesine 1 ayda giriş yapan geriatrik hastaların demografik verilerinin incelenmesi, hastaların ağzındaki kök-kanal tedavisi görmüş dişlerin insidansının belirlenmesidir. 


\section{Gereç ve yöntem}

Çalışmamız için gerekli etik onay "Marmara Üniversitesi Diş Hekimliği Fakültesi Etik Kurulu" tarafından alınmıştır. Araştırmamızda Marmara Üniversitesi'nde kullanılan ve hastaların yaş, cinsiyet gibi bilgilerinin yanı sıra röntgen bilgilerinin de elektronik ortamda depolanmasını sağlayan "Hasta Bilgi Yönetim Sistemi (HBYS)" veritabanı kullanılmıştır. HBYS veritabanına göre 2019 yılının Ocak, Şubat ve Mart aylarında fakülte hastanesine giriş yapan toplam hasta sayısı belirlenmiştir. Bu hastaların kaçının geriatrik hasta olduğuna bakılmıştır. Hastalar yaş grubu ve cinsiyetlerine göre kategorize edilmiştir:

Grup 1A: 65-69 yaş arası kadın hastalar

Grup 1B: 65-69 yaş arası erkek hastalar

Grup 2A: 70-74 yaş arası kadın hastalar

Grup 2B: 70-74 yaş arası erkek hastalar

Grup 3A: 75-79 yaş arası kadın hastalar

Grup 3B: 75-79 yaş arası erkek hastalar

Fakülte hastanesine 3 ayda (2019 Ocak - Şubat - Mart) başvuran geriatrik hastaların popülasyonu değerlendirildikten sonra bu 65 yaş ve üzeri olan bireyler içerisinden panoramik röntgeni bulunan herhangi 50 hasta seçilmiştir. Bu hastalar da aynı şekilde yaş grubu aralığ 1 ve cinsiyete göre kategorize edilmiştir:

Seçilen hastaların panoramik röntgenleri teker teker incelenmiştir. Kök-kanal tedavisi görmüş dişler belirlenmiştir.

\section{Bulgular}

Çalışma sonucunda elde edilen bulgular aşağıda sunulmuştur:

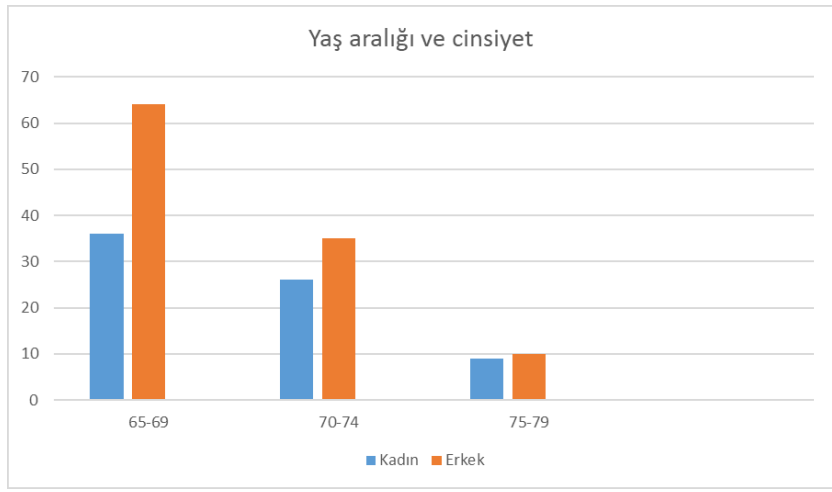

Tablo 1. Üniversite hastanesine 2019 yılının Ocak, Şubat ve Mart aylarında toplam 2762 hasta yeni giriş yapmıştır. Bu hastalar içerisinde 185 birey geriatrik hastadır.

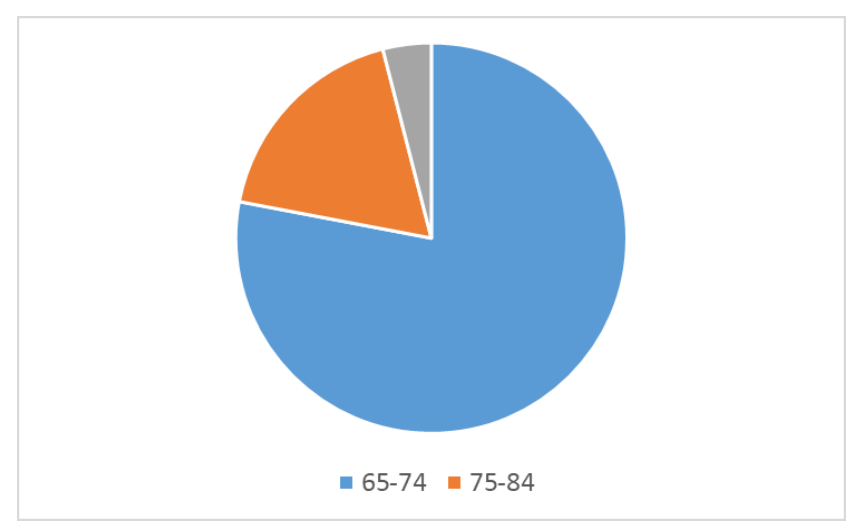

Tablo 2. Seçilen 50 geriatrik hastanın \%56'sını kadınlar, \%44'ünü erkekler oluşturmaktadır. 28 kadın hasta, 22 erkek hasta başvurmuştur.

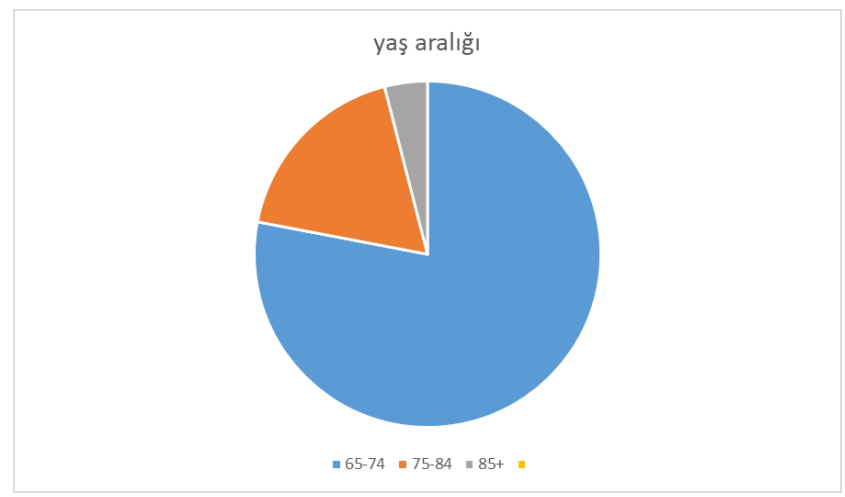

Tablo 3. Yaş dağılımı açısından incelendiğinde hastaların büyük çoğunluğu 65-74 yaş grubu içerisindedir. 65-74 yaş grubunda $39,75-84$ yaş grububda 9,85 yaş ve üzerinde ise sadece 2 hasta başvurusu görülmektedir.

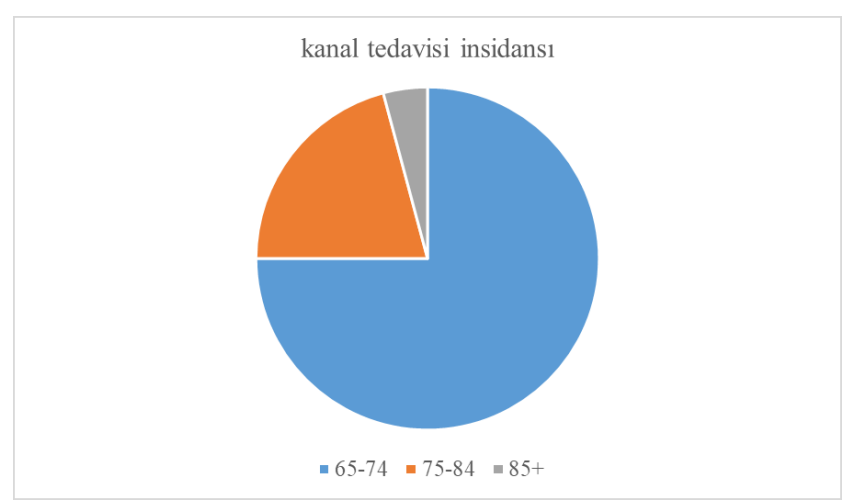

Tablo 4. Fakülte hastanesine başvuran geriatrik hastalar içerisinde 65-74 yaş grubunda 18 hastada, 74-85 yaş grubunda 5 hastada, 85 yaş ve üzeri hastalar içerisinde de 1 hastada kök-kanal tedavisi uygulanmıştır. 


\section{Tartışma}

Günümüzde, teknolojinin de gelişmesi ile birlikte yaşam beklentisi giderek artmakta ve yaşanabilecek sağlıklı yılların süresinin ve kalitesinin nasıl artırılabileceği önemli bir konu haline gelmektedir. Bu da 'kaliteli yaşlanma' y1 gündeme getirmektedir. 65 yaş üzeri hastaların tanısı, tedavisi, kişilerin sağlığının korunması, toplumdan soyutlanmadan yaşamlarını sürdürmeleri hedeflenmektedir.

Mevcut veriler, hasta seçimi ve sayısı, belirlenen sürenin kısitlı olmasından kaynaklanan bazı sınırlamalara rağmen geriatrik hastalar için temsili sayılabilir. Çünkü Türkiye içerisinde bir fakültesi hastanesi seçilmiş ve bu hastaneye başvuran geriatrik hastalar içerisinden rastgele 50 bireyin bilgileri üzerinde araştırma yapılmıştır. Aynı araştırma üniversite hastanesi yerine ağız diş sağlığı merkezinde yapılsayd 1 veriler ne olurdu bilmiyoruz. HBYS sisteminde panoramik röntgeni bulunmayan hastalar çalışmaya dahil edilmediğinden özellikle dişsiz hastaların çalışmaya dahil edilemediğini dolayısıyla verilerinin analiz edilemediğini düşünmekteyiz.

Çalışmamızda üniversite hastanesine gelen geriatrik hasta popülasyonu arasindan Hastalar cinsiyetlerine göre sınıflandırıldığında \%56 kadın, \%44 erkek hasta görmekteyiz. $\mathrm{Bu}$ oran 2017 TUiK verileriyle birebir örtüşmektedir. 65 yaş ve üzeri hastalarda kadın hasta popülasyonu daha fazladır. Kadınların ortalama yaşam süresinin dünya üzerinde de erkeklerden daha fazla olduğu bilinmektedir.

Fakülte hastanesine başvuran hastalarda en büyük yüzde dilimi genç -yaşlı diye adlandırabileceğimiz 65-74 yaş grubuna aittir. Bu yaş grubu içinden 39 kişi başvuru yapmıştır ve bu oran toplam geriatrik hasta sayısının \% 78 'ini oluşturmaktadır. 75-84 yaş aralığına sahip 9 birey başvuruda bulunmuştur, bu oran çalışmadaki toplam geriatrik hasta sayısının \%18'ini oluşturmaktadır. 85 yaş ve üzerinde ise 2 kişi başvuruda bulunmuştur, bu oran ise araştırmadaki toplam kişi sayısının \%4'ünü oluşturmaktadır.. Bu oran tuik 2017 verileriyle örtüşmemektedir. Bunun sebebinin yaşla birlikte ağızdaki diş sayısının toplumumuzda dramatik şekilde azalması olduğunu düşünmekteyiz. Yapılan çalışmalarda bir ağız ve diş sağlığı kurumuna başvuru yapan geriatrik hasta sayısı bizim bulduğumuz orandan daha fazladır. Sosyo-ekonomik nedenlerin de bu duruma yol açabileceğini düşünmekteyiz: Yaşla birlikte hareket güçlüğünün artması, fakülte hastanesine ulaşımın zorluğu sebepler arasında olabilir. Türkiye'de yatağa bağımlı olan geriatrik hastalar için mobil sağlık hizmetleri bulunmaktadır.
Hastaların ikamet ettiği yerlerde ağız diş sağlığı merkezleri de hizmet vermektedir. Bu sebeplerle, özellikle 75 yaş üstü hastaların üniversite hastanelerini daha az tercih ettiklerini düşünebiliriz.

Yaş grupları içerisindeki kök-kanal tedavisi insidansı değerlendirildiğinde, gelen hastaların yaş dağılımıyla bir uyum görülmektedir. 65-74 yaş grubu içerisindeki 39 hastadan 18'inin ağzında kök-kanal tedavisi bulunmaktadır. 75-84 yaş grubu arasındaki 9 hastanın 5'i ve 85 yaş ve üzeri 2 hastanın biri kök-kanal tedavisi görmüştür. Tüm yaş gruplarındaki hastaların yaklaşık yüzde ellisinin ağzında kök-kanal tedavisi tespit edilmiştir.

Katsoulis ve arkadaşlarının 2012 de yayınlanan çalışmasında bir geriatrik hastanedeki ağız ve diş sağlığı bölümündeki konsültasyonlar değerlendirilmiştir. Yapılan kohort çalışmada kötü ağız diş sağlığı ile genel sağlığın ilişkili olduğu görülmüş ve geriatrik hastalarda multidisipliner yaklaşımın önemi vurgulanmıştır (26).

Hamedy ve arkadaşları 2016'da yaptıkları meta-analiz çalışmasında geriatrik hastaların periapikal radyolusensi ve cerrahi olmayan kök-kanal tedavilerini değerlendirmişlerdir. Genel nüfusa oranla periapikal radyolusensi ve cerrahi olmayan kök kanal tedavisinin insidansı yaşlılarda daha yükssek görülmüştür. Bunun yanında kök kanal tedavili dişlerin içerisindeki periapikal radyolusensi insidansı daha düşük bulunmuştur (27).

Nalçacı ve arkadaşlarının 2007' de yayınlanan çalışmasında 65 yaş ve üzeri bireylerde ağız sağlığı, dişsizlik ve dişsizliğe etki eden faktörler incelenmiştir. Yapılan demografik çalışmada düşük okur-yazarlık seviyesine sahip hastalarda ve kadınlarda dişsizlik görülme insidansının daha yüksek olduğu bulunmuştur (28).

Sarılmaz ve arkadaşlarının 2016 kesitsel çalışmanın amac1 yaşlı bir Türk popülasyonunda 1768 kök kanal tedavisi görmüş dişlerdeki apikal periodontitis prevalansını belirlemek ve çeşitli faktörler ile periapikal durum arasındaki korelasyonu değerlendirmektir. Bulunan sonuçta ise endodontik tedavi ve koronal restorasyonun bir bütün halinde çok önemli olduğu vurgulanmıştır. Yaşlı popülasyonda başarısız kök-kanal tedavisi insidansı Hamedy ve arkadaşlarının yaptığı çalışmayla örtüşen şekilde yüksek bulunmuştur (29).

RutzdaSilva vearkadaşlarının2016'dayaptığıçalışmanın amac1, yaşlı hastalarda kök kanal obturasyonlarının kalitesi ile periapikal lezyonun varlığı / yokluğu arasındaki ilişkiyi araştırmaktır. Çalışmaya göre kök kanal obturasyonlarının 
kalitesi ile yaşlı hastalarda periapikal sağlık arasındaki ilişki konusunda bir fikir biriliği sağlanamamıştır (30).

Archana ve arkadaşlarının 2015 'te yaptığı çalışmanın amacı erişkin bir Hint popülasyonundan periradiküler radyolusensilerin prevalansını belirlemek ve kök kanal prosedürleri ile koronal restorasyonların kalitesini değerlendirmektir. Hindistan'da kök-kanal dolgulu dişlerde periapikal radyolüsensi prevalansı diğer popülasyonlardakine benzerdir. Yetersiz kök kanalı tedavisi ve başarısız koronal restorasyonlar periapikal radyolusensinin oluşmasıyla ilişkilendirilmişstir (31).

Hebling ve arkadaşlarının 2014'de yaptığı çalışmanın amacı, Brezilya'da yaşayan 450 yaşlı yaşlıda apikal periodontitis ve kök-kanal dolumlarının insidansını değerledirmektir. Yetersiz kök-kanal dolumu ile periapikal radyolusensi arasında anlamlı bir ilişki görülmüştür (32).

Bizim çalışmamızda hastaların demografik verileri ve kök kanal tedavisi insidansı incelenmiştir.

\section{Sonuç}

Çalışmamızda bir üniversite hastanesine gelen hastalar içerisindeki geriatrik hasta popülasyonunun kök-kanal tedavisi insidansı incelenmiştir. Yaşla birlikte kanal tedavisi insidansının azaldığı görülmüştür. Bu durumun sebebinin yaşla birlikte ağızdaki diş sayısının azalması olduğunu düşünmekteyiz. Bunun yanında ülkemizde yatağa bağımlı hastalar için mobil hizmetler verildiğinden ya da hastaların ikamet ettiği yerlerin yakınında başvurabileceği ağız diş sağlığı merkezleri olduğundan üniversite hastanesini tercih etmediğini düşünebiliriz.

\section{KAYNAKÇA}

1. Güler Ç. Yaşlılıkta Tanımlar Ve Yaşlılık Üzerine Söylenenler. Türk Geriatri Dergisi Geriatri. 1998;1(2):105.

2. YERTUTAN CAile ve Toplum Y1l: 1 Cilt: 1 Say1: 2 Haziran 1991 ISSN: 1303-0256.

3. WHO (1972) Psychogeriatric, report of a WHO Scientific Group, Technical Reports Series 507, Geneva. Cited in Davise AM. Epidemiology 185; 14(1):9-21.

4. WHO (1984) The uses of epidemiology in the study of the elderly. WHO, Technical Reports Series 706, Geneva:8

5. Bilir N, Paksoy N. Değişen dünyada ve Türkiye'de yaşlılık kavramı. In: Kutsal YG (ed).Temel Geriatri. 1. bask1. Ankara: Güneş T1p Kitabevleri; 2007. 3-9.

6. WHO. Active Ageing: A Policy Frame Work 2002.
7. Türk istatistik kurumu 2012 verileri. Erişim tarihi: 15.06 .2013 http://www.tuik.gov.tr/PreTablo.do?alt_id=37.

8. Boss GR, Seegmiller JE. Age-related physiological changes and their clinical significance. West J Med 1981;135:434-40.

9. Brooks SV, Faulkner JA. Skeletal muscle weakness in old age: underlying mechanisms. Med Sci Sports Exerc 1993;26:432-9.

10. Kinsella K, Wan H. U.S. Census Bureau, International Population Reports, P95/09-1, An Aging World: 2008, U.S. Government Printing Office, Washington DC 2009.

11. Yaman H, Akdeniz M, Howe J. GeroFam kavramı: Önümüzdeki demografik değişime yönelik bir çözüm önerisi. GeroFam 2010; 1(1): 1-14.

12. Active Aging A Policy Framework. http://whqlibdoc.who. int/hq/ (2002)

13. TÜİK (2014). İstatistiklerle yaşlilar dönemi. http://www. tuik.gov.tr/(15.12.2015).

14. Stuck AE, Aronow HU, Steiner A, Alessi CA, Büla CJ, Gold $\mathrm{MN}$, etal. A trial of annual in home comprehensive geriatric assessments for elderly people living in the community. N Engl J Med 1995;333:1184-9.

15. Stuck AE, Siu AL, Wieland GD, Adams J, Ru Benste in LZ. Comprehensive geriatric assessment: a meta-analysis of control led trials. Lancet 1993;342:1032 - 6.

16. Fox PC ( 1998). Acquired salivary dysfunction. Drugs and radiation. Ann NY Acad Sci 842: 132- 137.

17. Loesche WJ, Bromberg J, Terpenning MS et al ( 1995). Xerostomia, xerogenic medications and food avoidances in selected geriatric groups. J Am Geriatr Soc 43: 401- 407.

18. Narhi TO, Meurman JH, Ainamo A ( 1999). Xerostomia and hyposalivation: causes, consequences and treatment in the elderly. Drugs Aging 15: 103-116.

19. Streckfus CF ( 1995). Salivary function and hypertension: a review of the literature and a case report. J Am Dent Assoc 126: 1012- 1017.

20. Vissink A, van Nieuw Amerongen A, Wesseling $H$, 's-Gravenmade EJ ( 1992). Dry mouth; possible cause pharmaceuticals. Ned Tijdschr Tandheelkd 99: 103-112.

21. Kiyak HA (1986) Explaining patterns of dental service utilization among theelderly. J Dent Educ 50: 679-687.

22. Sreebny LM, Schwartz SS (1986) A reference guide to drugs and dry mouth.Gerodontology 5(2): 75-99.

23. Nazlıel H, Hersek N, Özbek M. Ağız Dokuları ve Sık Görülen Ağız ve Diş Sorunları. İçinde: Temel Geriatri Gökçe-Kutsal Y, Aslan D, Editörler, 1. Baskı Ankara: Öncü Basımevi, 2007: s.329-348.

24. Murray P.E. Stanley H.R. Matthews J.B. Sloan A.J. Smith A.J. Age-related odontometric changes of human teeth. Oral Surg Oral Med Oral Pathol Oral Radiol Endod 2002;93:474482.

25. Russel SL, Ship JA. Normal Oral Mucosal, Dental, Periodontal and Alveolar Bone Changes Associated with Aging. In: Improving Oral Health for the Elderly An Interdisciplinary Approach. Lamster IB, Northridge ME, Editors, 1th Edition, New York: Springer, 2008: p.233-246.

26. Katsoulis, J., Schimmel, M., Avrampou, M., Stuck, A. E., \& Mericske-Stern, R. (2012). Oral and general health status in 
patients treated in a dental consultation clinic of a geriatric ward in Bern, Switzerland. Gerodontology, 29(2).

27. Hamedy, R., Shakiba, B., Pak, J. G., Barbizam, J. V., Ogawa, R. S., \& White, S. N. (2016). Prevalence of root canal treatment and periapical radiolucency in elders: a systematic review. Gerodontology, 33(1), 116-127.

28. Nalçacı, R., Erdemir, E. O., \& Baran, I. (2007). Evaluation of the oral health status of the people aged 65 years and over living in near rural district of Middle Anatolia, Turkey. Archives of gerontology and geriatrics, 45(1), 55-64.

29. Sarıyılmaz, E., Keskin, C., \& Özcan, Ö. (2016). Retrospective analysis of post-treatment apical periodontitis and quality of endodontic treatment and coronal restorations in an elderly Turkish population. Journal of Clinical Gerontology and Geriatrics, 7(1), 17-20.
30. Rutz da Silva, F., Padilha, E. Z., Cândido, V. S., Cavassim, R., Pereira, A. C., \& Hebling, E. (2016). Relationship between quality of root canal obturation and periapical lesion in elderly patients: a systematic review. Gerodontology, 33(3), 290-298.

31. Archana, D., Gopikrishna, V., Gutmann, J. L., Savadamoorthi, K. S., Kumar, A. R. P., \& Narayanan, L. L. (2015). Prevalence of periradicular radiolucencies and its association with the quality of root canal procedures and coronal restorations in an adult urban Indian population. Journal of conservative dentistry: JCD, $18(1), 34$.

32. Hebling, E., Coutinho, L. A., Ferraz, C. C. R., Cunha, F. L., \& Queluz, D. D. P. (2014). Periapical status and prevalence of endodontic treatment in institutionalized elderly. Brazilian dental journal, 25(2), 123-128. 